\title{
Treatability studies on bleach effluent of pulp and paper industry by ultraviolet/hydrogen peroxide process with titanium dioxide as catalyst
}

\author{
L . Maria subashini *, Dr. S. Kanmani ${ }^{+}$ \\ * Assistant Professor, Jeppiaar Engineering College,Chennai. \\ ${ }^{+}$Professor, Centre for Environmental Studies, Anna University, Chennai.
}

\begin{abstract}
The treatment of bleach effluent from pulp and paper Industry for COD, colour and AOX removal was investigated using Ultra violet/Hydrogen peroxide process photocatalysed by Titanium dioxide. The Ultra violet / Titanium dioxide process was able to remove $48 \%$ and $37 \%$ of COD and colour. The Ultra violet / Hydrogen peroxide process was able to remove 52\% and 59\% of COD and colour. The combined process of Ultra violet/Hydrogen peroxide process photocatalysed by Titanium dioxide was found to be more effective in the removal of COD and organics compared with the individual processes at a $\mathrm{pH}$ of 7 . The combined process of Ultra violet/Hydrogen peroxide process photocatalysed by Titanium dioxide showed the COD, colour and AOX removal efficiency of $76 \%, 78 \%$ and $45 \%$ respectively.
\end{abstract}

Keywords: Photocatalysis, Ultraviolet/Hydrogen peroxide/ Titanium dioxide process, bleach effluent.

\section{Introduction}

The pulp and paper industry comes under twelve most polluting industries in India due to the huge quantity and quality of wastewater generated (Singh and Thakur, 2004). The manufacturing processes in the pulp and paper industries produce about $80 \mathrm{~m}^{3}$ of wastewater per ton of pulp produced (Almeida et al., 2004). More than 250 chemicals have been identified in effluents that are produced at different stages of papermaking (Ali and Sreekrishnan, 2001).

Among the various sections in pulp and paper mills, the bleaching section is considered to be the most polluted. During this stage, chlorine or chlorine dioxide is used to bleach pulp and release chlorinated and nonchlorinated compounds from lignin and wood extractives. Typically, these effluents contain high concentrations of chlorophenolic compounds, chloroacetones and chloroform, which are colored and recalcitrant. It has been reported that production of one ton of paper contributes $100 \mathrm{Kg}$ of color imparting substances and 2-4 Kg of organochlorines to the bleach plant effluents. The high chemical diversity of these pollutants causes a variety of clastogenic, carcinogenic and mutagenic effects on fishes and other aquatic communities in recipient water bodies (Parveen Kumar et al., 2011).

Worldwide, there are many existing biological and chemical treatment processes for paper and board mill effluent such as those based on aerobic, anaerobic, algal, fungal biomass, ozonation, electrochemical, photocatalysis, coagulation-flocculation treatment, etc. These classical treatments have been successful in lowering the chemical and biological oxygen demands (COD, BOD), but their applicability is limited by a great number of problems. Given the limitations of the current biological wastewater treatment, there is an increasing interest to develop a more effective treatment approach to reduce the impacts of pulp mill effluents on the environment (Marcia Regina et al., 2009).

Advanced oxidation processes (AOPs) are among promising technologies that have received increasing interest for the treatment of pulp and paper bleach effluents. Advanced oxidation processes (AOPs) are used to oxidize complex organic constituents found in wastewater that are difficult to degrade biologically into simpler end products. The most common advanced oxidation processes are $\mathrm{H}_{2} \mathrm{O}_{2}, \mathrm{UV} / \mathrm{O}_{3}, \mathrm{O}_{3}, \mathrm{UV} / \mathrm{H}_{2} \mathrm{O}_{2}$ and photochemical processes. Photochemical processes are used to degrade toxic organic compounds to $\mathrm{CO}_{2}$ and $\mathrm{H}_{2} \mathrm{O}$, without use of additional chemical oxidants because the degradation is assisted by high concentration of hydroxyl radicals generated in the process (Metcalf and Eddy, 2004).

The objectives of the study was to treat the bleach effluent sample by Ultra violet/Hydrogen peroxide process photocatalysed by Titanium dioxide for the removal of Organics and Colour and to study the effects of various operational parameters such as control conditions, $\mathrm{pH}$, catalyst dosage, catalyst reuse, Hydrogen peroxide concentration and contact time. 


\section{Materials and Methods}

\subsection{Bleach effluent from pulp and paper Industry}

Bleach Effluent sample was collected from the Kraft process of pulp and paper industry, where the industry used sugarcane bagasse and hardwood as the raw material.

\subsection{Ultraviolet/Hydrogen peroxide/ Titanium dioxide processes}

A Heber immersion batch photoreactor (UV) supplied Heber scientific, Chennai with a liquid volume of $1 \mathrm{~L}$ capacity was used. The reactor was placed in a photo chamber. A $400 \mathrm{~W}$ medium pressure mercury lamp with emission wavelength $365 \mathrm{~nm}$ was used as a light source in the photoreactor. Because temperature of the lamp influence on UV dose rate, the lamp chamber was cooled by circulated cold water and the temperature of the lamp was maintained at $20^{\circ} \mathrm{C}$ throughout the experiment. The cold water was supplied by the cooling water supply setup made by LAUDA GMBH \& Co, Germany of type WKL $230.1 \mathrm{~mL}$ magnetic stirrer supplied by Remi equipments private Ltd was kept below the sample tube for continuous stirring to get homogenous mixture. A $500 \mathrm{~mL}$ of wastewater sample was taken and required dosage of photocatalyst was added. Then the mixture was stirred for 5 minutes using magnetic stirrer to get a homogenous mixture. Then the sample was taken in the photoreactor. The cooling water was allowed to circulate around the UV lamp in the photoreactor. The magnetic stirrer was kept under the sample tube and switched on. The UV lamp was switched on and the photocatalysis sample was taken at required time interval. The sample was centrifuged at $2500 \mathrm{rpm}$ for duration of 20 minutes.

\subsection{Analytical control}

All samples were submitted to colour and COD analyses. The effluent discolouration was evaluated by measuring the absorbance at $465 \mathrm{~nm}, 525 \mathrm{~nm}$ and $620 \mathrm{~nm}$ with a UVVIS spectrometer. AOX measurements were made after pretreatment (Presto Filtration Unit) with activated carbon adsorption using ECS -120 AOX Analyser with ES- Boat water Module.

\section{Results and Discussions}

In this work, Kraft bleach effluent treatment was done by Ultraviolet/Hydrogen peroxide/ Titanium dioxide processes for 4 hours. The wastewater was characterised for the parameters such as $\mathrm{pH}$, COD, TDS, TSS, chlorides and colour as per standard methods. The wastewater has $\mathrm{pH}$ of 6.71 , TDS of $1470 \mathrm{mg} / \mathrm{L}$, TSS of $1524 \mathrm{mg} / \mathrm{L}, \mathrm{COD}$ of $1035 \mathrm{mg} / \mathrm{L}$, chlorides of $370 \mathrm{mg} / \mathrm{L}$ and AOX of $1.60 \mathrm{mg} / \mathrm{L}$. The characteristics such as colour, absorbance were measured by means of UV-VIS spectrophotometer. The characteristics of the bleach effluent used in this study are described in Table1.

Table 1 Characteristics of bleach effluent from pulp and paper industry

\begin{tabular}{|c|c|c|}
\hline SI. No. & Parameter & Value \\
\hline 1 & $\mathrm{pH}$ & 6.71 \\
\hline 2 & BOD & $835 \mathrm{mg} / \mathrm{l}$ \\
\hline 3 & COD & $1035 \mathrm{mg} / \mathrm{l}$ \\
\hline 4 & Colour & Brown \\
\hline 5 & Absorbance at $620 \mathrm{~nm}$ & 0.295 \\
\hline 6 & Chloride & $370 \mathrm{mg} / \mathrm{l}$ \\
\hline 7 & AOX & $1.84 \mathrm{mg} / \mathrm{l}$ \\
\hline
\end{tabular}

In the Ultra violet / Titanium dioxide process the effect of $\mathrm{TiO}_{2}$ dosage on the degradation of bleach effluent at its natural $\mathrm{pH}$ was studied by varying the $\mathrm{TiO}_{2}$ dosage from $0 \mathrm{~g} / \mathrm{L}$ to $1.0 \mathrm{~g} / \mathrm{L}$. The degradation of bleach effluent was determined by COD of the treated sample at various time intervals. It was found that maximum COD removal efficiency of $48 \%$ was achieved at a catalyst dosage of $1 \mathrm{~g} / \mathrm{L}$ for a contact time of 240 minutes. It was found that minimum of $19 \%$ COD removal efficiency takes place at a catalyst dosage of $0.4 \mathrm{~g} / \mathrm{L}$ for a contact time of 240 minutes. The degradation efficiencies based on the COD removal were calculated and they are illustrated in Figure. 1. $\mathrm{TiO}_{2}$ is capable for oxidation of a wide range of organic compounds into harmless compounds such as $\mathrm{CO}_{2}$ and $\mathrm{H}_{2} \mathrm{O}$ (Chatterjee and Dasgupta, 2005). $\mathrm{TiO}_{2}$ system increased the quantum efficiencies either by inhibiting electron-hole pair recombination through scavenging conduction band electrons at the surface of $\mathrm{TiO}_{2}$ or by offering additional oxygen atom as an electron acceptor to form the superoxide radical ion (Syoufian et al., 2008).

The effect of $\mathrm{TiO}_{2}$ dosage on the degradation of bleach effluent at its natural $\mathrm{pH}$ was studied by varying the $\mathrm{TiO}_{2}$ dosage from $0 \mathrm{~g} / \mathrm{L}$ to $1.0 \mathrm{~g} / \mathrm{L}$. The absorbance values of the untreated bleach effluent sample at $436 \mathrm{~nm}$, $525 \mathrm{~nm}$ and $620 \mathrm{~nm}$ was found to be $0.813,0.494$ and 0.295 respectively. The bleach effluent was treated using 
UV/Hydrogen peroxide process for 4 hours and the degradation of bleach effluent was determined by the percentage of Colour removal of the treated sample at various time intervals. It was seen that maximum colour removal efficiency of $56 \%$ takes place for a catalyst dosage of $0.8 \mathrm{~g} / \mathrm{L}$ for a contact time of 240 minutes at 525 $\mathrm{nm}$. It was seen that minimum colour removal efficiency of $23 \%$ takes place for a catalyst dosage of $0.4 \mathrm{~g} / \mathrm{L}$ for a contact time of 240 minutes at $620 \mathrm{~nm}$.

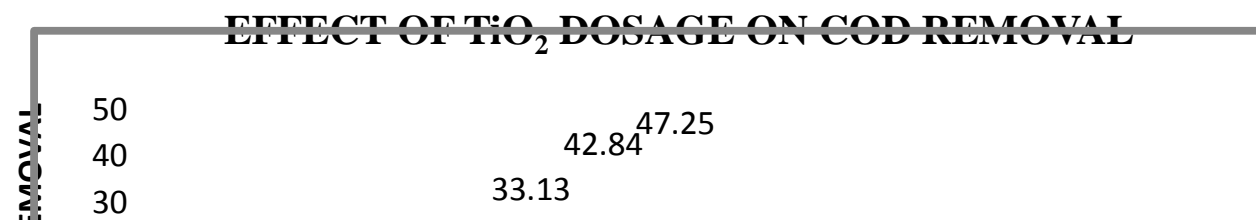

19.620

After 4

10

0

$\begin{array}{llllll}0 & 0.2 & 0.4 & 0.6 & 0.8\end{array}$

$\mathrm{TiO}_{2}$ DOSAGE IN g/l

Figure .1 The effect of $\mathrm{TiO}_{2}$ dosage on the COD removal of bleach effluent

The effect of contact time on COD removal of bleach effluent at its natural $\mathrm{pH}$ was studied by conducting the experiment for a contact time of 240 minutes at an optimum dosage of $1 \mathrm{~g} / \mathrm{L}$ and $\mathrm{H}_{2} \mathrm{O}_{2}$ concentration of $1.2 \mathrm{~mL} / \mathrm{L}$. Degradation of bleach effluent was determined by COD of the treated sample at various time intervals. It was found that that degradation efficiency of COD of the bleach effluent was found to be $40 \%$ after the first hour of treatment; it was $46 \%$ after the second hour of treatment, $59 \%$ after the third hour of treatment and $75 \%$ after the fourth hour of treatment. The degradation efficiencies based on the COD removal were calculated and they are illustrated in Figure.2. It was seen that the maximum COD removal efficiency of $75 \%$ was observed after a contact time of $240 \mathrm{~min}$.

Kumar Parveen et al., (2011) have studied the decolourization of the kraft bleaching waste water with $\mathrm{UV} / \mathrm{TiO}_{2}$ and $\mathrm{UV} / \mathrm{TiO}_{2} / \mathrm{H}_{2} \mathrm{O}_{2}$ advanced oxidation processes. It was seen that the maximum COD removal of 75\% was observed after a contact time of 240 min. Abhilasha Dixit et al., (2010) have studied the photochemical oxidation of phenol and chlorophenol aqueous solutions in a batch recycle photochemical reactor using ultraviolet irradiation, hydrogen peroxide and $\mathrm{TiO}_{2}$ (photocatalyst). The reaction was found to follow the first order kinetics and was influenced by the $\mathrm{pH}$, the input concentration of $\mathrm{H}_{2} \mathrm{O}_{2}$ and the dosing amount of the $\mathrm{TiO}_{2}$ photocatalyst. The results indicate maximum of $75 \%$ and $79 \%$ degradation of phenol and chlorophenol respectively within 90 minutes of radiation time.

The effect of contact time on colour removal of bleach effluent at its natural $\mathrm{pH}$ was studied by conducting the experiment for a contact time of 240 minutes at an optimum dosage of $1 \mathrm{~g} / \mathrm{L}$ and $\mathrm{H}_{2} \mathrm{O}_{2}$ concentration of $1.2 \mathrm{~mL} / \mathrm{L}$. The sample was collected and analysed for colour removal and the results and illustrated in Figure 2. Degradation of bleach effluent was determined by colour removal of the treated sample at various time intervals by measuring the absorbance of the treated bleach effluent sample at $436 \mathrm{~nm}, 525 \mathrm{~nm}$ and $620 \mathrm{~nm}$. Enhancement of $\mathrm{TiO}_{2}$-catalyzed photodegradation of organic compounds by several inorganic oxidants was mainly attributed to the increased electron scavenging from the extra oxidant sources ( $\mathrm{Hu}$ and Wang , 2003).

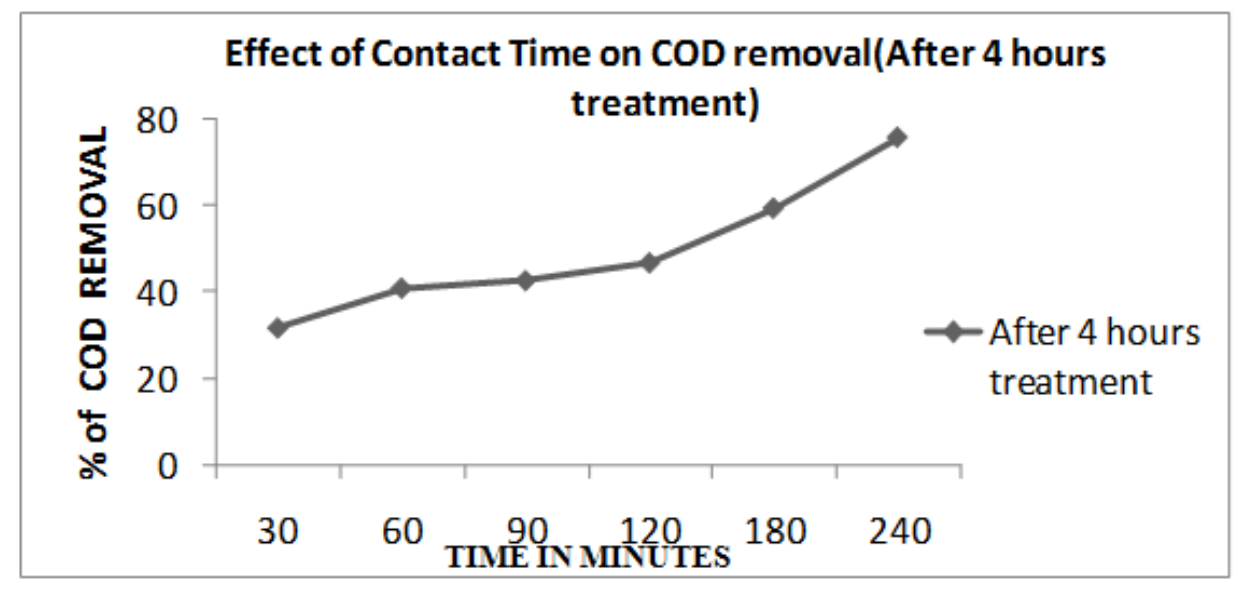




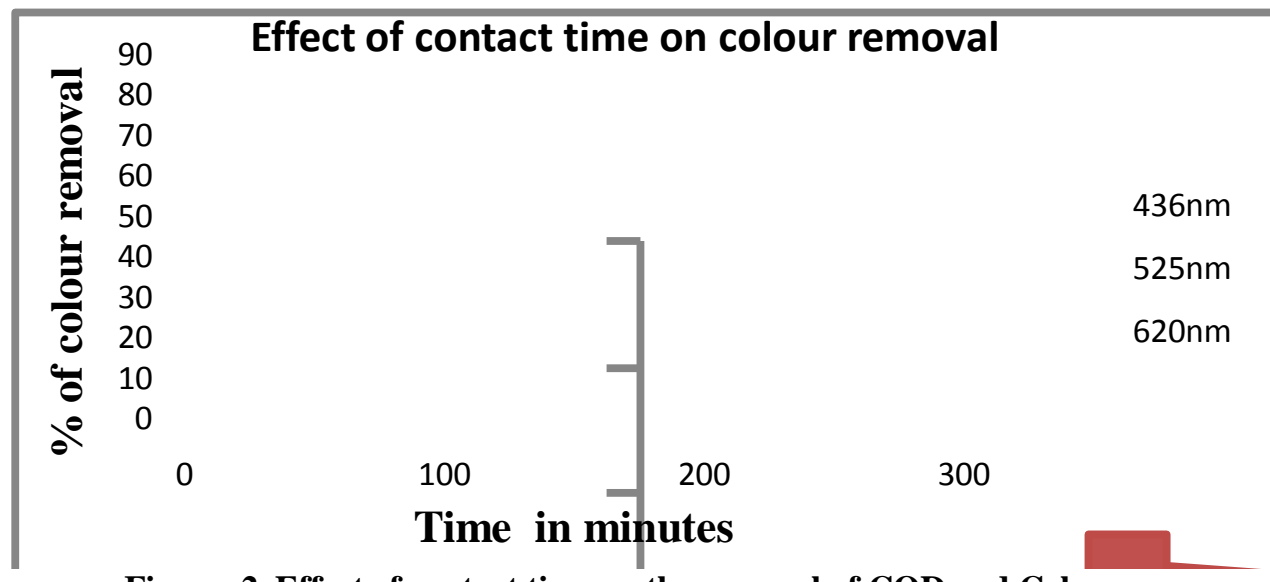

Figure .2. Effect of contact time on the removal of COD and Colour

The effect of $\mathrm{pH}$ on the degradation of wastewater was studied the for various $\mathrm{pH}$ viz 3, 5, 7 and 9 with optimum dosage of $\mathrm{TiO}_{2}$ and concentration of $\mathrm{H}_{2} \mathrm{O}_{2}$. The experimental results are presented in Table 4.8. The COD removal efficiency was found to be $22 \%$ at a $\mathrm{pH}$ of 3 . At a $\mathrm{pH}$ of 5 the degradation efficiency was found to be $37 \%$. The COD removal efficiency was found to be $47 \%$ at a $\mathrm{pH}$ of 9 . The degradation efficiencies are illustrated in Fig. 3. In this study, the maximum efficiency of degradation of $75 \%$ was observed at a $\mathrm{pH}$ of 7 at the end of 4 hours.

In this study, the natural $\mathrm{pH}$ of 7 gives significant rate of degradation. Hence the natural $\mathrm{pH}$ was selected for further studies. pH plays an important role both in the characteristics of pulp and paper industry effluents and in the reaction mechanisms that can contribute to degradation, namely, hydroxyl radical attack, direct oxidation by the positive hole and direct reduction by the electron in the conducting band. Ramakrishna (2001) found that at a $\mathrm{pH}$ of 3 to 5, the rate of degradation is high. $\mathrm{pH}$ has a significant effect on the surface charge of $\mathrm{TiO}_{2}$ at low $\mathrm{pH}$ the particles have a positive charge and at high $\mathrm{pH}$ a negative charge. Depending upon the charge of organic components present in solution, there may be electrostatic attraction or association between organic components and the $\mathrm{TiO}_{2}$ surface under $\mathrm{pH}$ conditions.

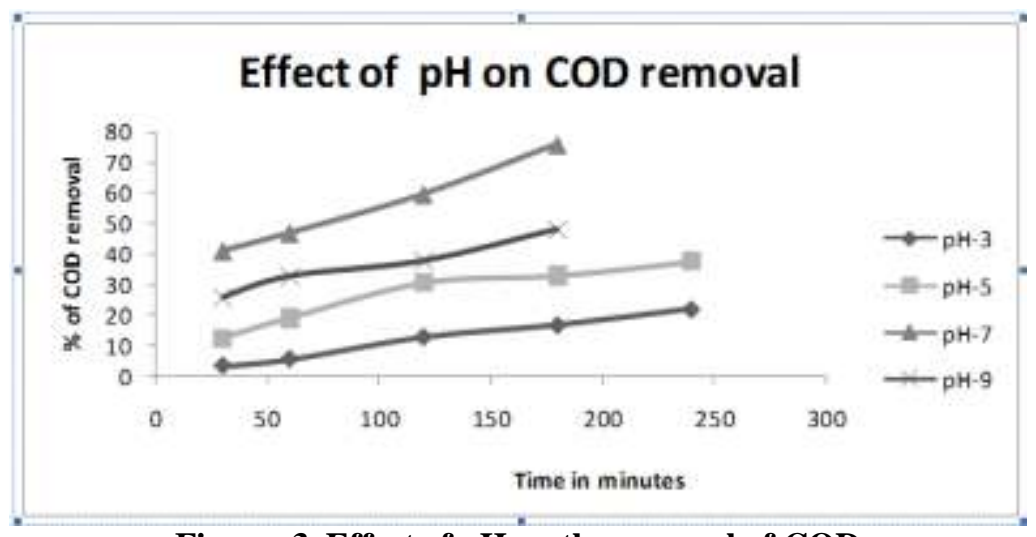

Figure .3. Effect of pH on the removal of COD

The sample of the bleach effluent was taken and photocatalysis was carried out under optimum conditions of $\mathrm{pH}$, catalyst dosage, $\mathrm{H}_{2} \mathrm{O}_{2}$ concentration and contact time and the sample was analyzed for the removal of AOX. The initial AOX concentration of the untreated bleach effluent sample was found to be 1.60 $\mathrm{mg} / \mathrm{l}$. The photocatalytic treatment of untreated bleach effluent sample was carried at an optimum catalyst dosage and $\mathrm{H}_{2} \mathrm{O}_{2}$ concentration for 4 hours and the AOX removal efficiency was calculated.

AOX measurements were made after pretreatment (Presto Filtration Unit) with activated carbon adsorption using ECS -120 AOX Analyser with ES- Boat water Module. The optimum catalyst dosage and $\mathrm{H}_{2} \mathrm{O}_{2}$ concentration was found to be $1 \mathrm{~g} / \mathrm{L}$ and $1.2 \mathrm{~mL} / \mathrm{L}$. The experimental results are presented in Table 4.10. The degradation efficiencies are illustrated in Fig. 4. The UV photocatalytic process is more favoured than the UV photolytic degradation process in the removal of AOX. The AOX concentration goes through a minimum when the concentration of $\mathrm{TiO}_{2}$ and $\mathrm{H}_{2} \mathrm{O}_{2}$ increase at constant $\mathrm{pH}$ and UV intensity (Mehmet Ugurulu et al., 2009). The toxic effects of AOX range from carcinogenicity, mutagenecity to very acute and chronic toxicity. 
The increase in the AOX concentration observed with only UV photo catalysis could result from the possible reaction of Chlorine molecules in the medium with degraded organic fragments reflecting the effect of UV photocatalysis. However, by adding $\mathrm{H}_{2} \mathrm{O}_{2}$ and increasing the concentration of $\mathrm{H}_{2} \mathrm{O}_{2}$, AOX concentration gets decreased. The maximum AOX removal efficiency was found to be $31 \%$.

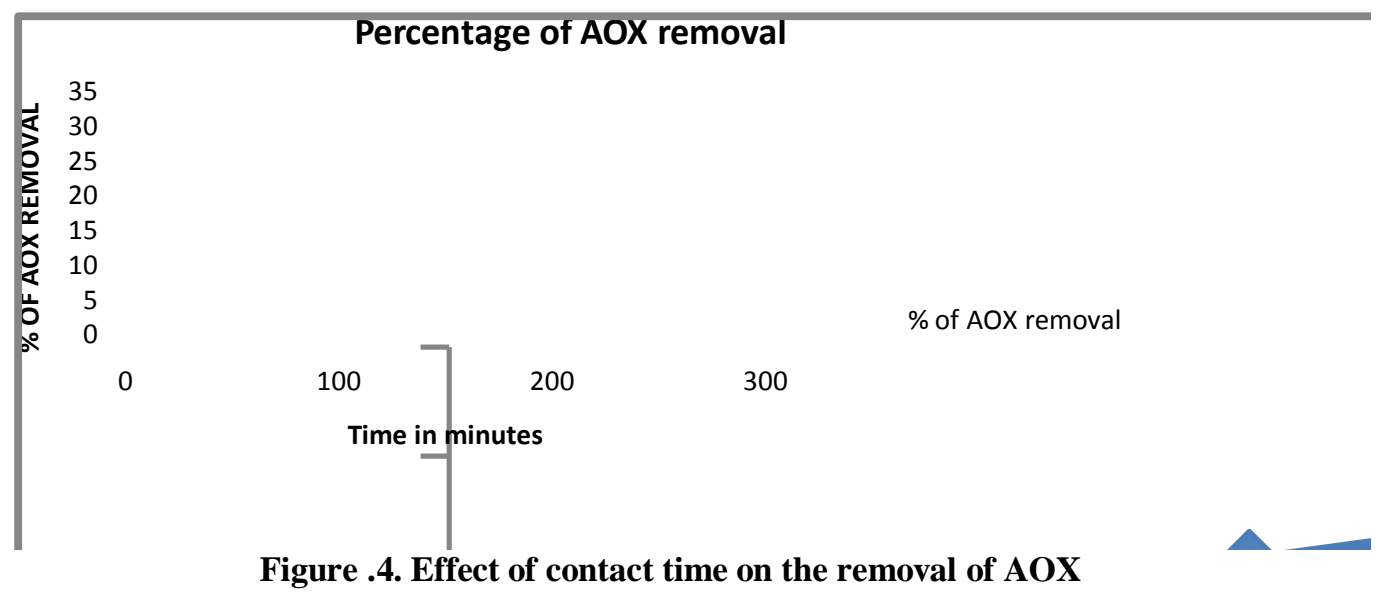

The graphical method was used to find the initial kinetic rate constant $(\mathrm{k})$ of the Ultra violet/Hydrogen peroxide process photocatalysed by Titanium dioxide for the removal of Organics from the bleach effluent sample. Rate constant derived from the pseudo-first-order kinetics was used to find the degradation of organic compounds. In order to find the initial rate of degradation, a plot of time vs $\ln \left(\mathrm{COD}_{0} / \mathrm{COD}\right)$ was made. Using the exponential equation it was found to be best fit for the degradation with $\mathrm{R}^{2}$ values of 0.923 . Hence, the rate of degradation of this wastewater followed the first order kinetics.

The kinetic rate constant (k) was found to be 0.002. Khare et al., (2004) observed that the plots were found linear for disperse dyes, which suggests that the COD removal reaction follows pseudo-first order kinetics. The kinetic results are shown in figure 4.10, which produce a single straight line. Therefore, the degradation of bleach effluent from the pulp and paper Industry follows a first order kinetic model. According to the degradation rate constant, obtained by plotting the graph between the time and the rate degradation it was found that the UV photocatalytic degradation processes are more effective than the UV photolytic degradation process for the treatment of paper-mill effluents.

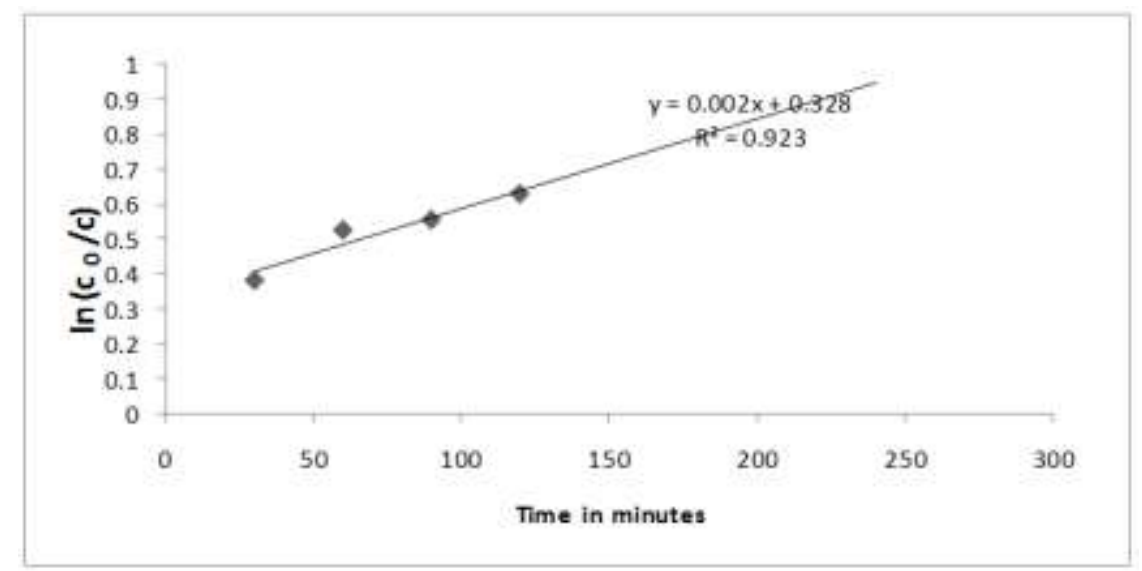

Figure 5.Determination of Kinetic Rate constant

\section{Conclusions}

Degradation of bleach effluent from pulp and paper industry wastewater is effective using Ultra violet/Hydrogen peroxide process photocatalysed by Titanium dioxide.At optimum conditions the maximum COD removal efficiency of $76 \%$ and colour removal efficiency of $78 \%$ was achieved after 4 hours treatment at a $\mathrm{pH}$ of 7 in the Ultra violet/Hydrogen peroxide process photocatalysed by Titanium dioxide. The maximum AOX removal efficiency of $31 \%$ was achieved after 4 hours treatment. The photocatalytic process can be considered a suitable alternative to the removal of organics and colour from the bleach effluent of pulp and paper Industry. 


\section{References}

[1] Almeida, Assalin E, Rosa M R, Duran N (2004), ' Treatment of presence of ozone', Quimica Nova, Vol. 27,pp. 818-824.

[2] Chatterjee D and Dasgupta (2005), 'Visible light induced photocatalytic degradation of organic Pollutants', J. Photochem. Photobiol, Vol. 6, pp.186-205.

[3] Hu C and Wang Y (2003), 'Decolorization and biodegradability of photocatalytic treated azo dyes and wool textile wastewater', Chemosphere, Vol.39, pp.2107-2115.

[4] Khare U K, Bose P and Vankar P S(2007), 'Impact of ozonation on subsequent treatment of azo dye solutions', J Chem Technol Biotechnol, Vol.82, pp.1012-1022.

[5] Marcia Regina Assalin, Edna dos Santos Almeida and Nelson Durán (2009), 'Combined System of Activated Sludge and Ozonation for the Treatment of Kraft E1 Effluent' Int. J. Environ. Res. Public Health, Vol. 6, pp.1145-1154.

[6] Mehmet Ugurulu,Hamdi Karaoglu M (2009), 'Removal of AOX,total nitrogen and chlorinated lignin from bleached kraft effluent by UV oxidation in the presence of hydrogen peroxide utilizing Tio ${ }_{2}$ as photocatalyst', Environ Sci Pollut Res, Vol.16, pp.265-273.

[7] Metcalf and Eddy (2004) 'Water and Wastewater Treatment' V Edition Tata

[8] Muna Ali and T.R. Sreekrishnan (2001), 'Aquatic toxicity from pulp and paper mill effluents,a review', Advances in Environmental Research, Vol.5, pp.175-196.

[9] Parveen Kumar, Satish Kumar, Nishi K Bhardwaj and Ashutosh Choudhary (2011), 'Advanced Oxidation of Pulp and Paper Industry', International Conference on Environmental and Agriculture Engineering', Vol. 15, pp. 170-175.

[10] Ramakrishna Varanasi (2001), 'Treatability Studies of Papermill effluents using Photocatalysis', M E Thesis Anna University.

[11] Singh P and Thakur I S(2004), 'Removal of colour and detoxification of pulp and paper mill effluent',Journal of Scientific and Industrial Research, Vol.63, pp.944-948.

[12] Syoufian A and Nakashima K (2008), 'Degradation of methylene blue In aqueous dispersion of hollow titania photocatalyst : Study of reaction enhancement by various electron scavengers', J. Coll. and Sci,Vol.317 pp.512. 